\title{
Five wavelength DFB fiber lase source
}

\author{
Varming, Poul; Hübner, Jörg; Kristensen, M.
}

\section{Published in:}

Proc. of OFC'97, Technical Digest

Link to article, DOI:

10.1109/OFC.1997.719663

Publication date:

1997

\section{Document Version}

Publisher's PDF, also known as Version of record

Link back to DTU Orbit

Citation (APA):

Varming, P., Hübner, J., \& Kristensen, M. (1997). Five wavelength DFB fiber lase source. In Proc. of OFC'97, Technical Digest (pp. 31-32). IEEE. https://doi.org/10.1109/OFC.1997.719663

\section{General rights}

Copyright and moral rights for the publications made accessible in the public portal are retained by the authors and/or other copyright owners and it is a condition of accessing publications that users recognise and abide by the legal requirements associated with these rights.

- Users may download and print one copy of any publication from the public portal for the purpose of private study or research.

- You may not further distribute the material or use it for any profit-making activity or commercial gain

- You may freely distribute the URL identifying the publication in the public portal

If you believe that this document breaches copyright please contact us providing details, and we will remove access to the work immediately and investigate your claim 


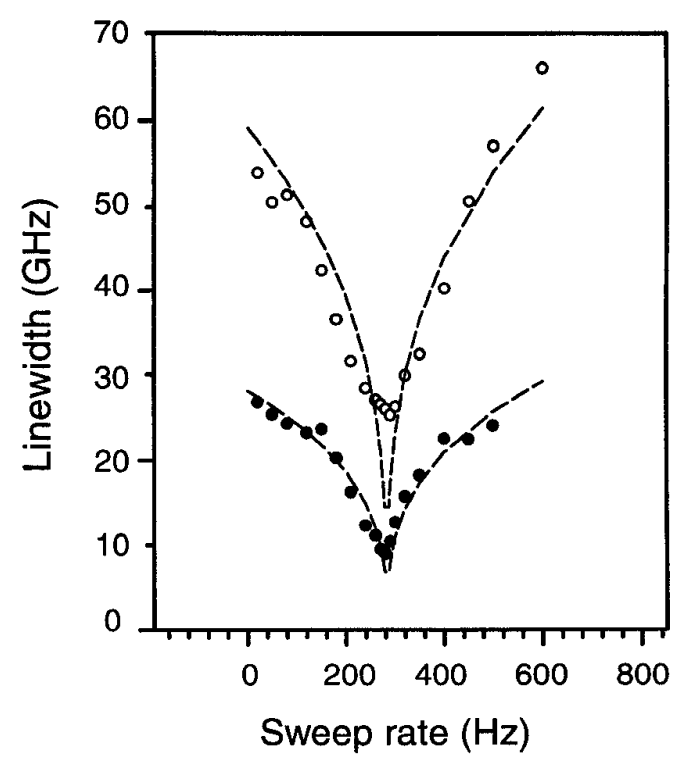

TuH3 Fig. 2. Instantaneous linewidth: (a) filled and open circles are experimental values at $3 \mathrm{~mW}$ and $100 \mathrm{~mW}$ output power, respectively. The dotted lines are theoretical fits, assuming the dependence of $\left(\mathrm{f}_{\text {sweep }}-\mathrm{f}_{\text {proper }}\right)^{1 / 3}$ with $\mathrm{f}_{\text {proper }}=$ $288 \mathrm{~Hz}^{2}$
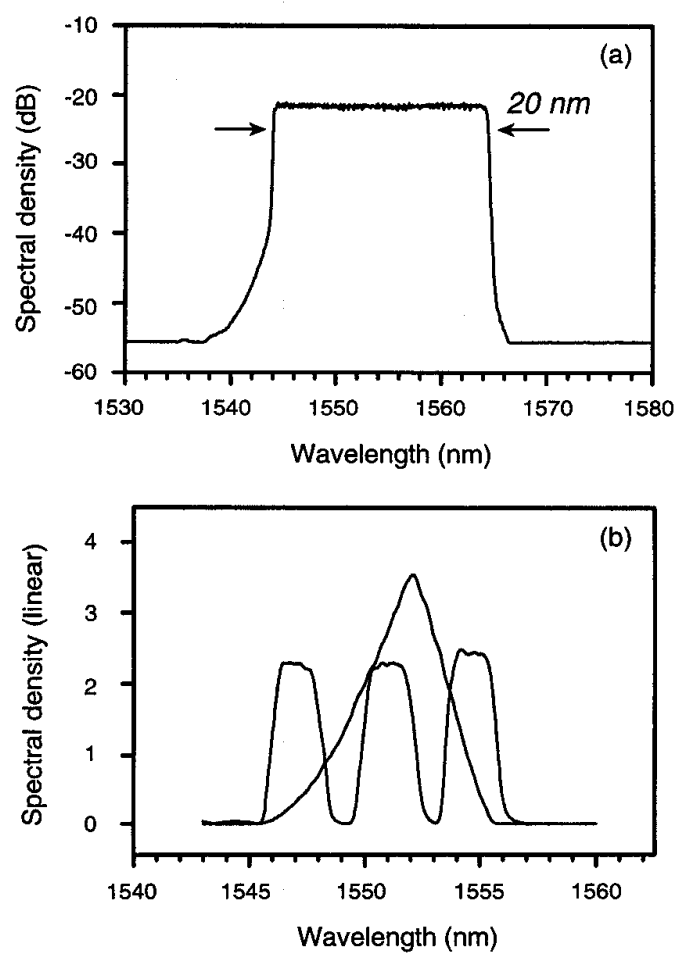

TuH3 Fig. 3. Peak-hold spectrum of the laser output: (a) AO frequency swept from $68 \mathrm{MHz}$ to $69 \mathrm{MHz}$ at fixed RF power giving flat spectral output over $20 \mathrm{~nm}$; (b) triangular and square modulated output obtained by synchronous modulation of the filter transmission and peak wavelength.

We investigated the laser performance under swept operation of the AOTF for a number of sweep ranges, functions, and rates. The timeaveraged laser output was monitored using an OSA and the instanta- neous linewidth determined by examining the temporal response of the laser output on reflection from a narrowband $(7 \mathrm{GHz})$ fiber grating. In particular we investigated sweep rates around the resonant case in which the filter peak is moved so as follow the $720 \mathrm{GHz} / \mathrm{ms}$ frequency shift imposed by the AOTF. For a 20 -nm sweep range this corresponds to a sweep rate of $\sim 288 \mathrm{~Hz}$. In Fig. 2 we plot measurements of the instantaneous linewidth as a function of sweep rate for the $20 \mathrm{~nm}$ sweep range case. The results clearly show a strong spectral narrowing at the resonant sweep rate in excellent agreement with our theoretical expectations. Moreover, the laser's natural tendency to pulse ${ }^{3}$ was suppressed. On resonance linear radiation moving under the filter peak experiences the lowest system loss making $\mathrm{cw}$ operation the preferred mode.

Figure 3(a) shows the peak-hold spectrum obtained by resonant tracking of the acoustic frequency shift over $20 \mathrm{~nm}$ for a fixed acoustic power. The sweep frequency and the output power were $290 \mathrm{~Hz}$ and 100 $\mathrm{mW}$, respectively. The spectral shape and output power were almost independent of the sweep rate up to $7 \mathrm{kHz}$. Sweep ranges $>38 \mathrm{~nm}$ were readily achieved. In Fig. 3(b) we show that control of the spectral form can be achieved with synchronous frequency and amplitude modulation. Triangular and square wave modulated forms were chosen for this purpose.

In summary, we have reported a wavelength-swept fiber laser with up to 38-nm sweep range, $<0.1 \mathrm{~nm}$ instantaneous linewidth, user definable spectral shape, and $>100 \mathrm{~mW}$ output power. We believe such sources to have great potential for use in applications requiring accurate spectral control or measurements.

*Department of Physics, Korea Advanced Institute of Science and Technology, Taejon 305-701, Korea

1. P.F. Wysocki, M.J.F. Digonnet, B.Y. Kim, Opt. Lett. 15, 879 (1990).

2. W. Streifer and P. Saltz, IEEE J. Quantum Electron. 9, 563 (1973).

3. H. Sabert and E. Brinkmeyer, IEEE J. Lightwave Technol. 12, 1360 (1994).

\section{TuH4}

2:45pm

\section{Five wavelength DFB fiber laser source}

\author{
Poul Varming, Jörg Hübner,* Martin Kristensen,* Department \\ of Electromagnetic Systems, BIdg. 349, Technical University \\ of Denmark, DK-2800 Lyngby, Denmark; E-mail: \\ pv@emi.dtu.dk
}

Stable single-mode laser sources with narrow linewidth are key components in high-capacity wavelength-division multiplexed (WDM) optical communication systems. Distributed feedback (DFB) ${ }^{1-3}$ and distributed Bragg reflection (DBR $)^{4}$ fiber lasers are compact devices, which are able to provide stable single-mode operation. They are inherently fiber compatible and cascadable. ${ }^{2}$ We present a multiwavelength laser source consisting of five fiber DFB lasers spliced together and pumped by a single 60-mW 1480-nm semiconductor laser.

Each laser is fabricated individually using 5-cm erbium-doped fiber spliced to dispersion-shifted fiber and equipped with standard pigtails using angled connectors. The erbium-doped fiber has a dopant concentration of $1.5 \times 10^{25} \mathrm{~m}^{-3}$, core diameter of $4 \mu \mathrm{m}$, and a numerical aperture of 0.27 (supplied by Lycom A/S). The Bragg gratings are photoinduced using a $\mathrm{KrF}$ excimer laser illuminating a $5 \mathrm{~cm}$ long phasemask (fabricated by QPS) with 248 -nm light. The fluence on the fiber is around $0.4 \mathrm{~J} / \mathrm{cm}^{2}$ per pulse. After around 3000 pulses the $4.2 \mathrm{~cm}$ long gratings 


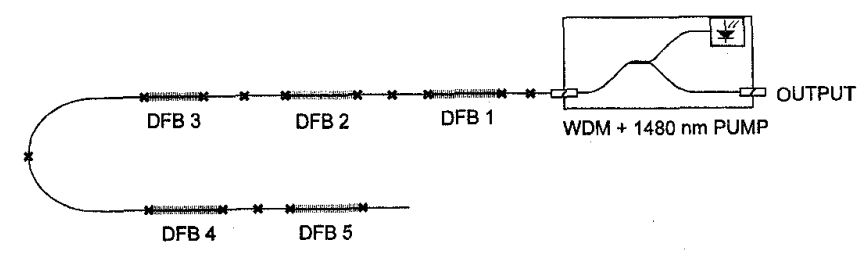

TuH4 Fig. 1. Experimental setup for the five-wavelength DFB fiber laser source (crosses indicate fusion splices).

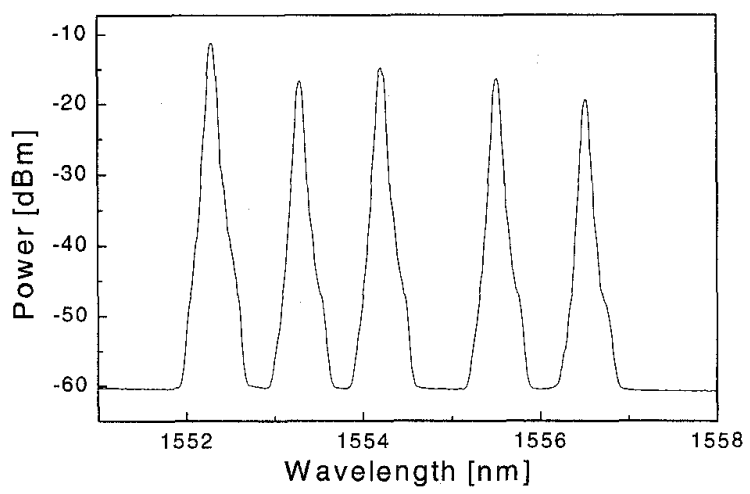

TuH4 Fig. 2. Optical spectrum of the multiwavelength DFB fiber laser, measured with $0.05-\mathrm{nm}$ resolution.

had a peak reflectivity of $99 \%$ corresponding to a grating strength $\mathrm{kL}$ of around three. A phase shift was then induced in the central part of the grating by additional UV exposure. To ensure a proper phase shift each laser was pumped with a $1480-\mathrm{nm}$ semiconductor laser while the phase shift was induced. The lasing was monitored on a spectrum analyzer and a scanning Fabry-Perot interferometer with a free spectral range of 7.5 GHz.

The lasers show high temperature stability. Longitudinal and polarization single-mode operation without mode hopping has been verified continuously from room temperature up to $200^{\circ} \mathrm{C}$ as well as at $-196^{\circ} \mathrm{C}$.

All lasers are written with a single phasemask. The wavelength is determined by the applied stress on the fiber during the writing process thereby changing the grating period when releasing the fiber. A wavelength change of about $5 \mathrm{~nm}$ can be achieved without breaking the fiber. The wavelength reproducibility of our current setup is around $0.2 \mathrm{~nm}$.

After UV-writing the lasers, the angled pigtails are cut off and the lasers are spliced together and pumped with the same $60-\mathrm{mW}$ semiconductor laser operating at $1480 \mathrm{~nm}$ (see Fig. 1), thereby forming a multiwavelength source. The peak wavelength separation is $1 \mathrm{~nm} \pm 0.1 \mathrm{~nm}$. Figure 2 shows the output from the five lasers. The difference in lasing power is mainly due to relatively low pump power in combination with not fully optimized splicing.

In conclusion, we demonstrated a stable five-wavelength source suitable for WDM systems. The design principle is easily scaleable to eight wavelengths. The position of the individual wavelength can be placed more precisely by using a customized phasemask for each desired wavelength.

${ }^{*}$ Mikroelektronik Centret, Bldg. 345 e

1. P. Varming, J. Hübner, M. Sejka, in IOOC'95, Technical Digest, Vol. 5, paper PD1-3.
2. M. Sejka, J. Hübner, P. Varming, M. Nissov, M. Kristensen, in Optical Fiber Communication Conference, Vol. 2, 1996 OSA Technical Digest Series Optical Society of America, Washington, D.C., (1996), paper TuJ2.

3. J.T. Kringlebotn, J.-L. Archambault, L. Reekie, D.N. Payne, Opt. Lett. 19, 2101-2103 (1994).

4. V. Mizrahi, D.J. DiGiovanni, R.M. Atkins, S.G. Grubb, Y.-K. Park, J.-M.P. Delavaux, IEEE J. Lightwave Technol. 11, 2021-2025 (1993).

TuH5 (Invited)

3:00pm

Analysis of fiber-grating-coupled semiconductor lasers for WDM applications

J.E. Sipe, L. Ramunno, Department of Physics, University of Toronto, Toronto, M5S 1 A7 CANADA and Ontario Laser and Lightwave Research Centre

A novel external-cavity geometry for a semiconductor laser can be constructed by coupling the laser light through an antireflection coating on the laser diode face into a fiber, some distance along which a Bragg grating is written in the fiber core. The grating forms one mirror defining the cavity, a high reflectivity coating on the back end of the diode serving as the other mirror. Design options include the choice of length of fiber providing the external cavity, as well as the choice of grating type-with respect to both bandwidth and chirp-written in the fiber core.

Much of the early interest in this device focused on actively modelocking the laser to provide a soliton pulse source. ${ }^{1}$ After reviewing the work in this area, we will turn to cw operation, where in certain circumstances the stability against mode hopping has been observed to depend on the chirp of the Bragg grating. ${ }^{2}$ A simple physical picture of such behavior is possible because the cavity round trip time is much greater than the transit time of the light in the gain medium. This picture will be outlined, and used to explore the range of behavior possible when the laser is directly modulated. Recent theoretical and experimental studies focusing on applications for wavelength-division multiplexing will be discussed.

1. See, e.g., P.A. Morton et al., IEEE Photon. Technol. Lett. 7, 111-113 (1995), and references cited therein.

2. P.A. Morton et al., Appl. Phys. Lett. 64, 2634-2636 (1994).

TuH6

3:30pm

\section{Broader and flatter supercontinuum spectra in dispersion-tailored fibers}

J.W. Lou, T.J. Xia, O. Boyraz, C.-X. Shi, G.A. Nowak, M.N. Islam, Department of Electrical Engineering and Computer Science, University of Michigan, 1301 Beal Avenue, Ann Arbor, Michigan 48109-2122

We show that using dispersion-shifted dispersion-decreasing (DD) fiber can enhance the supercontinuum (SC) generation process in comparison to constant dispersion or dispersion-increasing (DI) fiber. For example, we show that at $24.3 \mathrm{~W}$ peak input power, flatter spectra and twice the spectral broadening are obtained with $\mathrm{DD}$ fiber. SC sources are important for applications in multiwavelength systems and testing, as exemplified by the recent use of SC sources in $400-\mathrm{Gb}$ 's telecommunication applications. ${ }^{1-3}$ The use of DD fiber is advantageous because 